\section{Nuclear promise or nuclear peril?}

\author{
Siegfried S. Hecker
}

This article is an edited transcript of the plenary presentation delivered by Siegfried S. Hecker of Stanford University at the 2010 Materials Research Society Spring Meeting on April 7, 2010 in San Francisco.

\section{Introduction}

Twould like to thank MRS officials for inviting me and I extend my congratulations to all of the award recipients. It is a particular pleasure to return to MRS and to talk about the intersection of science and policy, since so much of this session is dedicated to the wonderful work in materials science. While MRS President David Ginley just mentioned that materials is about making "stuff," my talk is focused on how not to destroy "stuff." Specifically, I will talk about the intersection of science and policy in the nuclear arena. Nuclear issues are in the news daily: Just yesterday President Obama announced his administration's new nuclear policy; tomorrow he will go to Prague to sign the new Strategic Arms Reduction Treaty with Russia; and next week he will host a world nuclear security summit, where leaders from 47 nations will join him to discuss ways to deal with nuclear dangers around the world. Nuclear energy can electrify the world, but it can also destroy it, as suggested in the title of my talk "Nuclear promise or nuclear peril?"

Let me begin with some examples. Today, we find nuclear dreams everywhere; for example, last December in the United Arab Emirates, the South Korean Korea Electric Power Corporation signed a $\$ 20$ billion contract to build four nuclear reactors on the Gulf, in Abu Dhabi, to provide electricity for this incredible desert metropolis. Why in the world would they want to produce electricity when they have oil and gas? The answer is quite simplethey can sell oil and gas to the rest of the world, while they obtain electricity from an almost inexhaustible source.

Regarding nuclear peril, one need look no further than North Korea, where Kim Jung Il is developing nuclear weapons, and I will discuss this in detail later.

\section{Nuclear ambition or nuclear nightmare?}

President Ahmadinejad and Iran's ayatollahs are exercising their sovereign right to develop nuclear energy, but many around the world are concerned that they may also be developing nuclear weapons, which would make the Gulf a nightmare. Anuclear "Walmart" was developed by A.Q. Khan, shown in Figure 1, a metallurgist by training. After developing an illicit import network to help his native Pakistan build the bomb, Khan ran an export business with the help of greedy European businessmen and other partners around the world. Together they provided the means to make the nuclear materials to build the bomb to countries such as Libya, North Korea, and Iran.

How the world has changed. During the Cold War we relied on a policy of mutually assured destruction so as not to annihilate the world as a result of a poten-

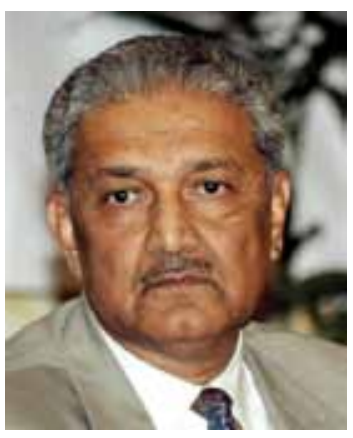

Figure 1. A.Q. Khan, called the father of Pakistan's nuclear bomb and leader of a global nuclear proliferation network. tial, massive nuclear exchange between the Soviet Union and the United States. Just one example of how massive the nuclear arsenals became is the Soviet doomsday bomb, or "Tsar's Bomba." Figure 2 shows a photograph of Russian academician Yuri Trutnev, who along with Andrei Sakharov, designed it to yield the equivalent of 100 megatons of TNT. To scientists dealing with nanotechnology and nanomaterials, a megaton probably does not mean much, but it is very large; for example, the bombs that destroyed Hiroshima and Nagasaki were approximately 13 and 20 kilotons, respectively. So, this bomb has 5,000 times the explosive power of the bomb that destroyed the Japanese cities. Trutnev told me, "Of course, Sig, that bomb was strictly for political purposes." It was exploded on October 30, 1961 at Novaya Zemlya, an island above the Arctic Circle, at 50 megatons, half of its design yield, because Sakharov was concerned about health effects from its radioactive fallout. During the Cuban Missile Crisis, less than a year later, the world may indeed have been "One Minute to Midnight," as Michael Dobbs' recent book by that title points out. Krushchev's decision to station nuclear weapons in Cuba, partially in response to the United States' stationing them in Turkey, was retracted only after the Soviet Union and the United States came close to nuclear war.

The world changed dramatically when the Cold War came to an end with the dissolution of the Soviet Union. Many people took a deep breath and said, "Now we are free of the nuclear peril." However, the nuclear peril did not disappear, it only changed. Almost overnight, nuclear dangers changed from the annihilation of humankind, to the threat caused by the Soviet Union's collapse and Russia's inability to protect its own weapons and materials and to take care of the stewards of the bomb: the people in the laboratories, the factories, and the military. Suddenly we were threatened more by Russia's weakness than its strength.

Russia's political and economic system changed overnight and the institutions that ran the Soviet Union collapsed, including those that provided for the secu- 


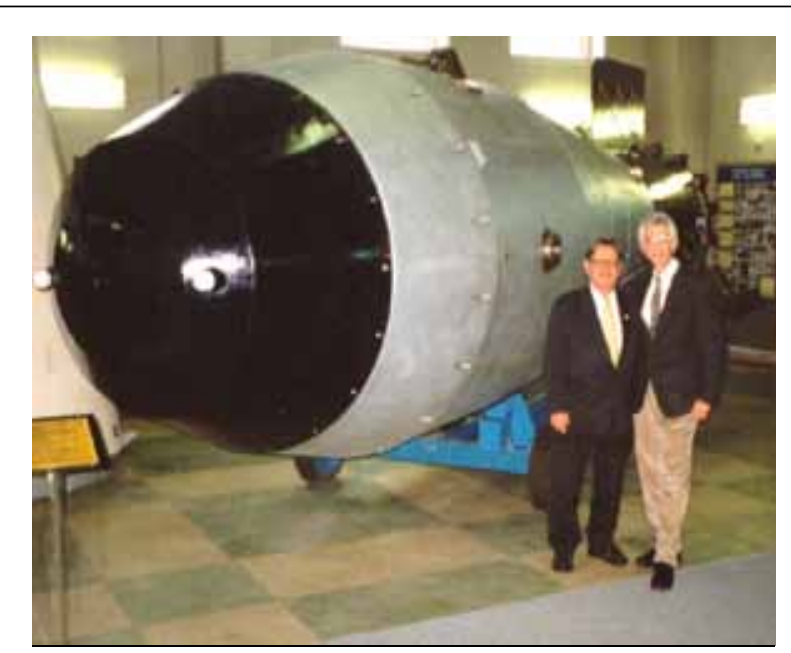

Figure 2. Siegfried S. Hecker (right) with academician Yuri A. Trutnev and a photo of the "Tsar Bomba" model in the Sarov, Russia museum.

rity of the nuclear enterprise and the welfare of its workers. Four nuclear nations were born out of one on December 25, 1991 when President Gorbachev dissolved the Soviet Union: In addition to Russia, Ukraine, Kazakhstan, and Belarus were left with nuclear arsenals. Thanks to the Nunn-Lugar Cooperative Threat Reduction Program, the nuclear weapons in the other three countries were returned to Russia. However, along with Russia, they had dozens to hundreds of facilities with nuclear materials that posed grave security risks and were now vulnerable because the key institutions collapsed and each country was economically destitute. All in all, the Soviet Union had more than a million kilograms of highly-enriched uranium and plutonium, the fissile materials that can fuel a bomb; and much of it was now not well protected.

\section{Why is nuclear energy so important?}

Most people understand the basic facts and the reason nuclear energy is so different from other energy sources; splitting the nucleus, or fusing nuclei together, releases millions of times the energy compared to tapping the energy of electronsthat is, millions of electron volts compared to a few eV. Figure 3 shows that nuclear energy has millions of times the energy density of conventional fuel sources, such as wood and coal. The same factor of millions is true for nuclear explosives compared to TNT.

The elements that can be split in a practical fashion are the actinides, particularly some isotopes of uranium and plutonium. The actinides are of interest because the nuclei are large enough and unstable enough that they can be split. As one moves past plutonium in the actinide series, the elements past americium split even more easily, but their half lives are too short to be useful. The elements of interest are uranium, neptunium, plutonium, and americium, but the only two "good" bomb materials (if there is such a thing) are uranium and plutonium. The factor of millions derives from the nucleus, but the most fascinating aspect of the actinides is their electronic structure: It controls all other properties. In fact, the electronic structure and the properties of the actinides are much more interesting to me than their nuclear properties. From thorium to plutonium the $5 f$ electrons participate in bonding, much like the $d$ electrons in transition metals, but then become localized (non-bonding) at americium and beyond. The transition occurs right at plutonium. Consequently, plutonium is the most complex element in the periodic table. Plutonium may be a physicist's dream because of the complexity of the behavior of the $5 f$ electrons, but it is an engineer's nightmare because it is that behavior that makes it so complex and unstable. The slightest change in temperature, pressure, and chemistry can change its behavior dramatically.

The factor of millions was recognized immediately after the discovery of fission in 1938 in Germany, and that it could be used for either military or peaceful pur-

"S.S. Hecker, "The Complex World of Plutonium Science," MRS Bulletin, 26 (9) (2001) p. 672 in the theme dedicated to plutonium, "Challenges in Plutonium and Actinide Materials Science." poses. It was developed first for military purposes by the United States during the Manhattan Project because of concern about Hitler's Germany, although the bombs were used at Hiroshima and Nagasaki to end the war against Japan. But the dilemma - nuclear peril on one hand and promise on the other-was also recognized immediately, and no one understood this better than President Eisenhower, who was the Supreme Allied Commander in Europe during World War II. In December 1953, the year he became President, he delivered a speech at the United Nations that launched the "Atoms for Peace" Program, which he hoped would help "to hasten the day when fear of the atom will begin to disappear from the minds of people and the governments of the East and West." He added these powerful words "the United States pledges before you-and therefore before the world - its determination to help solve the fearful atomic dilemma - to devote its

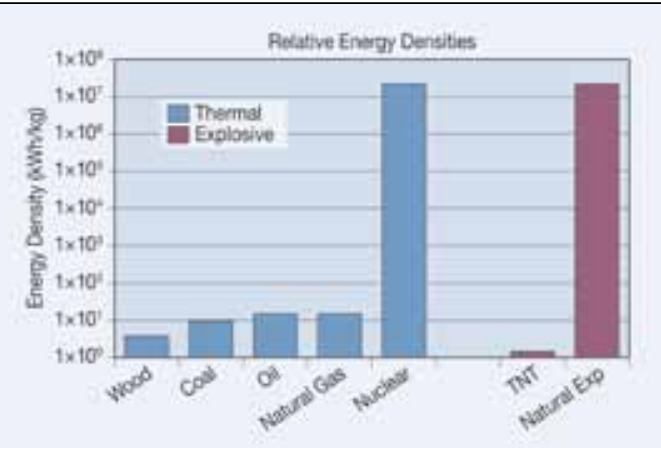

Figure 3. Energy density of various forms of energy.

entire heart and mind to find the way by which the miraculous inventiveness of man shall not be dedicated to his death, but consecrated to his life."

\section{What have we achieved in developing the peaceful potential of the atom?}

Nuclear electricity did not become as inexpensive as some people predicted in the early $1950 \mathrm{~s}$, but it does supply $16 \%$ of the world's electricity today. As shown in Figure 4, it varies greatly throughout the world from nearly $80 \%$ in France to $20 \%$ for the United States, but only 3\% for India and 2\% for China, two countries with a large fraction of the world's popu- 


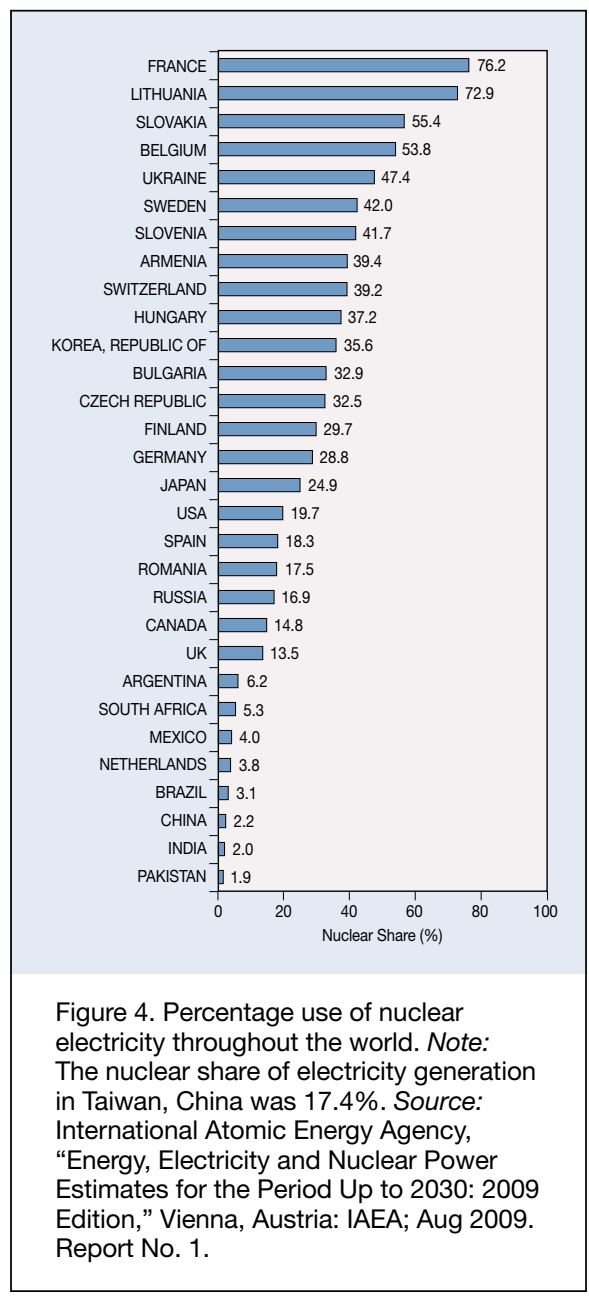

lation. If there is to be a nuclear renaissance, it will be driven by the fact that nuclear energy offers a sustainable, affordable, and carbon-friendly source of energy that is available on a scale that could make a difference in helping control climate change. Of the carbon-friendly energy sources such as hydro, solar, and nuclear, nuclear energy supplies threequarters of that energy today. However, nuclear energy is used primarily in the developed world, whereas major expansion of nuclear energy will likely be in the developing world; predominantly in China and India. The principal challenge for a nuclear renaissance is economic; nuclear power plant operation today is as economic as any other source of energy. However, in the United States, we have made it difficult and expensive to build new nuclear plants. Safety is an equally serious challenge. Although the safety record of the nuclear industry has been superb since improvements were made following the Three Mile Island and Chernobyl nuclear accidents, it will be a challenge to continue that record if three to ten times as many nuclear power plants are built around the world. Likewise, the security of nuclear plants to sabotage or terrorist attacks must be ensured.

Waste disposal has been a weak spot for the nuclear industry. Although some technical challenges remain, the primary challenges are societal. This is one area where we scientists have not done well in interfacing with the rest of society; we have not worked well with the public to find a solution that is acceptable both from technical and societal points of view.

\section{Nuclear proliferation}

I will devote the rest of the talk on my greatest concern: the potential spread of nuclear weapons or the possibility of nuclear materials getting into hands of terrorists and leading to an improvised nuclear device. Concerns about nuclear proliferation stem from the nature of the nuclear fuel cycle rather than the reactor itself. The fuel cycle is comprised of the front end; the mining, milling, making of fuel and enrichment (some reactors, such as light-water reactors, require that the concentration of uranium- 235 is increased from its natural level of $0.71 \%$ to $3 \%$ or $4 \%$ ). The nuclear fuel is then burned in a reactor. The back end of the fuel cycle is the disposal of the waste or the extraction of some of the byproducts, including plutonium, which is created from uranium-238 by neutron capture. The front and back ends represent potential proliferation pathways. At the front end, enrichment facilities can potentially be diverted to continue to enrich past the 3-5\% levels used for most commercial reactors to reach bomb grade of 80 $90 \%$. At the back end, plutonium extracted from burned, or spent, uranium fuel can potentially be used to make bombs. In fact, the military fuel cycle, which is run to make plutonium for bombs, and the commercial fuel cycle, which is run to produce electricity, have the same technological base.

Figure 5 shows a nuclear fuel cycle schematic. On the left is the plutonium path, which can be used to make plutonium for bombs. Natural uranium can be used directly if neutrons in the reactor are moderated, or slowed down, with heavy water or graphite. Cooling is typically accomplished with gas for graphitemoderated reactors and either light or heavy water for heavy water-moderated reactors. Both can produce good bombgrade plutonium once it is chemically separated from the spent fuel. On the right side of the diagram, the uranium path, enriching it to $3-5 \%$ allows uranium to be burned in light water reactors, from which we obtain electricity, but the waste also contains plutonium, which in this case is less suitable for bombs. No country has ever taken that path to build a bomb. However, the facilities can potentially be diverted to enrich uranium beyond light water reactor levels to bomb grade. I will discuss this in more detail; suffice it to say for now that North Korea took the lefthand path to the bomb, while Iran is proceeding along the right-hand path.

Let us look at two aspects of prolifera- 
tion. Concerns about vertical proliferation arise from nuclear weapon states building bigger and better nuclear arsenals. For the most part, that process has been significantly reversed in the past 20 years, and the new START Treaty that President Obama will sign tomorrow takes another small but important step in that direction. Horizontal proliferation is the spread of nuclear weapons to additional countries. We are particularly concerned about a potential domino effect; for example, if Iran develops nuclear weapons, would it lead to other countries in the Middle East to do the same? The Nuclear Nonproliferation Treaty, or NPT, signed in 1968, was a pact among states with and without nuclear weapons to stop the spread of such weapons. Those nations that had demonstrated nuclear weapons with nuclear tests by that time, namely, the United States, Russia, the United Kingdom, France, and China, would share nuclear technology for peaceful purposes with non-nuclear weapon states if they agree to not pursue nuclear weapons. The five nuclear weapon states also agreed to eliminate their nuclear arsenals eventually. As helpful as the NPT has been to assist nations with civilian uses of atomic energy, it also allows nations to possess fissile materials and, hence, come close to having the potential for nuclear weapons, which is the situation in Iran. The NPT also allows states to withdraw in their supreme national interest, which is what North Korea did. Concern about proliferation arises from a combination of technical capability and political intent. During the Cold War, the world was reasonably simple; countries were in one of two camps, they were protected either by the Soviet Union or by the United States. The end of the Cold War changed the intent side of the equation significantly because that protection vanished in many cases. Now we are also dealing with a potential renaissance, which could lead to three to five times as many nuclear reactors and more countries in the fuelcycle business.

Figure 6 shows the number of countries that have developed the bomb and when they are believed to have done so. This number is much smaller than the 15 to 20 states that President Kennedy feared we would have by the end of the 1960s. The jump in the curve coincides with the dissolution of the Soviet Union when Russia, Ukraine, Kazakhstan, and Belarus inherited Soviet nuclear weapons that were eventually returned to Russia. South Africa also developed the bomb, but relinquished it. India and Pakistan tested in 1998 and North Korea followed in 2006. Although the increase in states with nuclear weapons has been reasonably slow, we are concerned that many more states have the potential capability to build the bomb because they possess fissile materials or parts of the fuel cycle that would allow them to make and divert fissile materials for military use. More than 30 countries now possess such a latent capacity and a nuclear renaissance may increase that number.

\section{Barriers to proliferation}

The barriers to proliferation are best constructed by a combination of institutional, political, and technical means. Institutionally, one could operate enrichment facilities multi-nationally to guard against nations diverting their commercial enrichment facilities to military use. One could also arrange for fuel guarantees and back that up with an international fuel bank to limit the number of countries that would insist on building their own enrichment facilities.

Assured fuel supplies will also require political cooperation, as will controls on exports of technologies that would allow countries to build their own enrichment capabilities or their own reprocessing facilities. Transparency is key. For example, Japan has a latent nuclear capability because it has reactors, enrichment facilities, and reprocessing, but their nuclear facilities are fully open to international inspection. Iran's nuclear facilities are only partially open for inspection, and it is not cooperating fully with international inspectors causing serious international concern that it is developing the nuclear weapon option.

There are also important technological barriers, but they must be used together with institutional and political barriers to be effective. For example, one of the greatest concerns is the security and safeguarding of fissile materials, principally uranium-235 and plutonium-239. These materials must be physically protected, controlled, and accounted for. Technologies for detection, monitoring, tagging, and forensics are important. Also, with the renewal of interest in nuclear power, research is again being done on new reactor designs, new fuel cycles, and new waste disposal methods. We have done little in the United States in these areas for nearly 30 years. India, for example, has a much more vigorous and exciting program than the United States has.

On the bright side of the proliferation picture, several countries have either abandoned their nuclear weapons program or the weapons themselves. Muammar Gadaffi relinquished Libya's nuclear weapons ambitions in 2003. He decided he preferred to join the greater international community and gain access to international financial backing upon giving up his nuclear ambitions. South Africa's intent also changed. South Africa built highly-enriched bombs in the 1970s and 1980s, but relinquished them after the dissolution of the Soviet Union and before apartheid fell. Saddam Hussein was trying to build nuclear weapons 
before the first Gulf war and lost that capability as a result of losing the war and having to submit to intense international inspections. It turns out he never came close to regaining a weapons capability.

I will now provide some detail on several instructive examples. As mentioned, the United Arab Emirates have big nuclear plans, and I believe they are following the right path. They have contracted to purchase four reactors from South Korea, which is emerging as a significant industrial giant not only in the electronics and automobile industries, but also the nuclear industry. The United Arab Emirates have agreed not to develop the front or back ends of the fuel cycle, which represents the proliferation danger. They want to set an example of how to develop nuclear power without increasing proliferation concerns.

\section{Iran}

Iran, on the other hand, is developing nuclear power the wrong way. President Ahmadinejad proclaimed just last week that there is no way that the international community can stop Iran from its sovereign right to enrich uranium. He has boasted in public about Iran's capabilities, including leading media tours into quite sensitive facilities. Iran not only has developed uranium enrichment facilities, such as those in Natanz, but they also have a large Russian-built light water reactor, which is now ready to fuel. The reactor itself is not the problem. The problem is that from 1987 to 2003, Iran secretly developed uranium enrichment capabilities. Once this clandestine operation became public, Iran allowed international inspectors to examine the facilities; at the same time they built another secret facility in Qom, which was discovered only last year. In addition, Iran is building a plutonium reactor in Araq that is within a few years of operation and will be able to produce more than a bomb's worth of plutonium per year once operational. We know that Iran has sufficient uranium deposits and uranium ore processing capabilities for a weapon program, but they lack sufficient uranium for a robust nuclear power program. It has also been reported that some of their military facilities have performed tests that are suspiciously close to tests specifically used for nuclear weapons development rather than for a peaceful nuclear program. They also have a vigorous missile program. In other words, today Iran does not have the bomb or bomb fuel, but they have everything in place to give them a nuclear weapon option. They have continued to shorten the time it would take them to build nuclear weapons if they decide to do so.

\section{North Korea}

I have had the opportunity to visit North Korea six times and its nuclear complex three times in a non-official, nongovernmental Track II manner. I have published my assessment, based on these visits and on my studies, in the Winter 2010 issue of the Daedalus magazine ${ }^{\dagger}$ North Korea has sufficient plutonium for four to eight bombs. I believe that their nuclear weapons are of primitive design. I do not believe that they have been able to miniaturize the bombs to fit them on a missile. They have conducted two underground nuclear tests; the first in 2006 was not very successful, but the second in 2009 was likely quite successful. North Korea has a very ambitious short- and medium-range missile program. They also have a long-range program that has not been very successful, but it is still of concern. In late 2002, the Bush Administration accused North Korea of taking the second path to the bomb-uranium enrichment-while they had agreed to a freeze of the plutonium path to the bomb. North Korea then withdrew from the Nonproliferation Treaty in 2003 and built the plutonium bomb. I think the concern about uranium enrichment was well founded in terms of research, but does not appear to have been well founded in terms of industrial capacity. In other words, we traded the risk of having a bomb perhaps a decade or 15 years from then, for one that took them three months to build—not a good

†Siegfried S. Hecker, "Lessons learned from the North Korean nuclear crises," Daedalus, Winter (2010) p. 44. An additional article has now been published: Siegfried S. Hecker, Sean Lee, and Chaim Braun, "North Korea's Choice: Bombs over Electricity," National Academy of Engineering, The Bridge, June 2010, p. 5. risk assessment. So, in my opinion, North Korea, has the bomb but a limited nuclear arsenal. That bomb is not a military bomb, but they used it effectively for political purposes.

\section{India and Pakistan}

Both India and Pakistan demonstrated their nuclear weapons capability with tests in 1998. They have not been at peace since the division of the subcontinent in 1947. Although I will not dwell on this aspect of the problem, the Indian subcontinent has the greatest potential for a military clash involving nuclear weapons. Instead, I want to bring India's nuclear program to your attention because it is, in my opinion, the most ambitious and also the most creative nuclear energy program in the world today. India decided many years ago that it would develop this program in three stages. Their first reactor was a pressurized heavy water reactor, built for them by the Canadians with some U.S. supplies. They continued developing pressurized heavy water reactor technology indigenously. In 1974 they tested their "peaceful" nuclear device, which was followed by strict international sanctions against India's nuclear program. So for 35 years India sat outside the world's "nuclear tent" and developed its own capabilities.

India is building plutonium fast breeder reactors for its second stage. President Carter terminated the U.S. breeder program in the late 1970s, and there are still no plans for reviving the breeder reactor development in the foreseeable future. India's breeder program is very ambitious and moving ahead quickly. I visited its 500-megawatt electric breeder reactor in Kalpakkam. It is scheduled to start operation in 2012. The third stage moves to a thorium fuel cycle, in which thorium, instead of uranium, is used for reactor fuel. India has plentiful thorium deposits, but insufficient uranium for its commercial power program. The reason I raise the Indian nuclear power issue is my concerns about safety and security. While India was ostracized from the international nuclear community, it also had insufficient contact and cooperation with the international community concerned about safety and 
security of nuclear reactors and nuclear fuel cycle facilities. The U.S.-India nuclear deal orchestrated by the Bush Administration brought India back into the international community. It was important to bring India back into that community although the deal sets a bad precedent for the international nonproliferation regime because India never signed the NPT. India needs energy; it has ambitious plans for increasing its nuclear electricity contribution. It will be very important to work closely with India to make sure its nuclear plans are achieved safely and securely.

\section{The threat of nuclear terrorism}

President Obama calls nuclear terrorism his biggest concern. In addition to the danger of more nations acquiring nuclear weapons capability, we are concerned that governments may lose control of nuclear materials or nuclear weapons. In my opinion, the most likely route is not that a nuclear weapon will be stolen or diverted, but rather the fissile materials may be. There are more than 2 million kilograms of highly-enriched uranium and plutonium in the world, and some of it is not well protected. Terrorists may get hold of it and potentially build an improvised nuclear device. Technical specialists say that nuclear weapons are the most complex devices that have ever been built on earth, so one might ask, "Could terrorists really build them?" Harold Agnew, a former director of the Los Alamos National Laboratory, put it best. He said that people who say it is easy for terrorists to build a bomb are wrong, but people who say it is impossible are "dead wrong." In my opinion, given sufficient fissile materials, eventually some terrorist group will be able to build a bomb and explode it.

The crucial barrier is to keep fissile materials out of the hands of terrorists. If we consider that there are more than 2 million kilograms of fissile materials in the world, then even a safeguards system that protects, accounts, and controls for 99.99 percent of all materials, will leave us with an uncertainty of enough material to build about five bombs. Therefore, the protection and safeguarding of fissile materials is a major issue, which requires better interna- tional cooperation than ever before. As stated earlier, the concern for the security of Russia's enormous stockpile of fissile materials was particularly grave in 1992, right after the dissolution of the Soviet Union. During the Cold War, the Soviets did a good job of protecting their nuclear enterprise. They did it with guns, guards, and gulags. But those days were over; the gulags are gone, as were some of the guns and guards for a while, and the rest of the guards were hungry. I have been to Russia 41 times since 1992 working with the Russians mostly on this problem.

The biggest nuclear threats today Next, I briefly discuss what I see as the six biggest nuclear threats today. This is my list, not an official U.S. government view. My ranking is based on the concern that governments may lose control of nuclear materials, which could come into the hands of terrorists, who would build a nuclear device and explode it somewhere in a major city in the world. Such a device may not be $100 \%$ effective, but even a bomb with a yield of 2 kilotons, which is $10 \%$ of the yield of the Nagasaki bomb, exploded in New York City or another major city could kill a few tens of thousands of people. So, this threat is serious.

Number 1 is Pakistan, because it has highly-enriched uranium, plutonium, missiles, and the bomb; it also has Osama bin Laden somewhere near its border and A.Q. Khan, and its government is not very stable - truly a great concern.

Number 2 is not a specific country, but there are many reactors in some 40 countries of the world that use highlyenriched uranium fuel, and that fuel could be used for bomb fuel if it is not sufficiently protected. The United States and Russia, along with the International Atomic Energy Agency, have done a great deal in the past 10 years to protect these materials or convert the reactors to use low-enriched uranium; but not enough.

Number 3 is Russia. In 1992, Russia was number 1,2 , and 3 on my list and today there is still much fissile material there, better protected, but not well enough; and it still does not have a modern, comprehensive safeguards system today.

Number $\mathbf{4}$ is North Korea. I am not so much worried that it would lose control of the materials or sell it, but rather it might help somebody else build the capability to make the material.

Number 5 is Iran. It does not yet have the fissile material, but once Iran has it, it will move to number 2 .

Number $\mathbf{6}$ is a place hardly anybody talks about; Kazakhstan, which was part of the Soviet Union. It relinquished its nuclear weapons, but did not give up all its nuclear material. Kazakhstan was the home of the Soviet nuclear test site, which is much larger than the Nevada test site. I have concerns about what was left at the test sites when the Soviets abandoned it in 1992 and the nuclear materials associated with Kazakhstan's reactors and in the remains of its industrial complex.

The United States has done a lot to work with all of these countries, partly under the auspices of the Nunn-Lugar Cooperative Threat Reduction program, but much more needs to be done. That is also why President Obama has called for the World Nuclear Security Summit to address these problems worldwide.

\section{Visits to North Korea}

Finally, I will give a brief description of nuclear North Korea, based on my six visits. One of my Stanford colleagues, Professor John Lewis, asked me to go to North Korea in January 2004. The reason the North Koreans invited us was that in 2003 after they withdrew from the NPT, they extracted the plutonium from the spent fuel rods that had been in a storage pool since 1994, and they built the bomb. They were surprised that nobody seemed to care, and they wanted some respect from the United States. In 2003, President Bush was occupied elsewhere in the world, so the United States did not pay much attention to North Korea.

The North Koreans took us to the reactor, the spent fuel pool, and to the reprocessing facility. At the closeout of the site tour in the reprocessing facility conference room, they tried to convince me that they now had a nuclear deterrent. I told them I had seen the facilities and talked to the technical people about PUREX (the process by which plutonium is separated from spent fuel) and about plutonium 
metallurgy, but I could not conclude they had a deterrent. They then asked if I would like to see their product. I said, "Do you mean the plutonium?" and they said, "Why yes." They knew I had been at Los Alamos and worked on plutonium. When they brought the plutonium into the conference room, I wound up holding a sealed marmalade glass jar containing 200 grams of plutonium metal, in my hand. It had a very complicated shape, which would be difficult to make out of unalloyed alpha plutonium; hence I knew it was the face-centered cubic delta phase of plutonium. We continued our technical discussion during this fascinating visit to a place I never expected to see. $\$$

During each of my subsequent visits, the North Koreans had a very specific message they wanted me to take back to the U.S. government. I provided the details in my recent Daedalus article. Although North Korea has been in the nuclear business for more than 50 years, they have been trying to work with the United States to trade in their antiquated reactor, which is good for making bomb-grade plutonium, but not so good for generating electricity, for a modern light water reactor, which is good at generating electricity, but does not make good bomb-grade plutonium. For a variety of complicated political reasons, either they or the United States have backed away from such a trade. In the end, North Korea decided to use the plutonium generated in their reactor and build nuclear weapons. We must assess what the greatest threats are of the North Korean nuclear program; in my opinion, it is not the possession of nuclear weapons, but the possibility of export of nuclear materials or nuclear technologies.

We were concerned about import of technologies into North Korea for uranium enrichment, while they were exporting uranium hexafluoride to Libya. They built a plutonium-producing reactor in Syria, which would be one of our greatest proliferation concerns today, but the Israelis destroyed it; the Syrians actually helped, because they cleaned up the mess in order to destroy the evidence of having a reactor.

\$The first visit and impressions were reported in MRS Bulletin: S.S. Hecker, "The Nuclear Crisis in North Korea," MRS Bulletin, 29 (11) (2004) p. 782.
They still deny it today.

North Korea has had the bomb for at least seven years, possibly 17 years, but they have not used it yet in anger. We are now once again at a stage at which a bold approach to North Korea is required; we cannot get them to relinquish the bomb voluntarily and we cannot force them since a military option is not viable. We cannot pressure them to give it up because China will not agree to sanction North Korea seriously. China views North Korea very differently than we do. They do not want North Korea to have the bomb, but they do not want to risk North Korea's regime to collapse in order to relinquish the bomb. China wants peace and stability on the Korean Peninsula; it considers the downfall of the regime a threat to peace and stability. We must work with China to have it help reduce the risk of nuclear exports from North Korea. With China's help we must try to contain North Korea in the near term and then find a long-term solution, which, in my opinion, will have to include a light water reactor. Unfortunately, the main obstacle to that is U.S. domestic politics because it is politically difficult for the administration to try a bold approach at this time given the current situation.

I want to leave you with some thoughts about the people of North Korea. I enjoyed visiting Russia 41 times, North Korea six times, India four times, China a dozen times or so, and Kazakhstan a couple of times. I found that, in addition to being a technical person, it was necessary to understand the people, the societies, and the culture because the potential of misuse of nuclear energy is determined by capability and intent; and intent depends on all these things. North Korea looks different from other societies, and, of course, it is controlled by a terrible regime. It has a terrible human rights record, but it has good people living there. I visited a school where students were conducting physics experiments; I sat with a young lady in Pyongyang's Middle School Number 1, who had composed a beautifully written essay on Thomas Alva Edison, although North Koreans are supposed to hate all Americans; we heard a beautiful musical performance by students, and looking at the young people's faces, it was hard to conclude that this is a rogue state. Looking around the streets of Pyongyang, I saw a mother with her little children, flowers, and people waiting at bus stops, and so on. What must happen in North Korea is not for us to try to blast them out, but for the people themselves to eventually decide not to tolerate the sacrifices they have had to make over the years. The regime has managed to keep reform at bay, but it is fighting a losing battle.

Let me conclude with one example using a photo (Figure 7), which I took in November 2006. We were coming out of the Pyongyang subway and I saw a young man about 11 years old, who was wearing the mandatory blue school uniform along with the red bandana for the revolution. He was also wearing a light brown jacket because it was November, but there was something I found totally incredible on his head; he was wearing a baseball cap, backwards, with a Nike "swoosh." When that kid is 21 years old, they are not going to be able to keep him "down on the farm." My thought at that time was "Where there is swoosh there has to be hope."

Thank you for your attention.

Siegfried S. Hecker is a research professor in the Stanford University Department of Management Science and Engineering, a senior fellow at FSI, and co-director of Center for International Security and Cooperation. $\mathrm{He}$ is also an emeritus director of Los Alamos National Laboratory. 


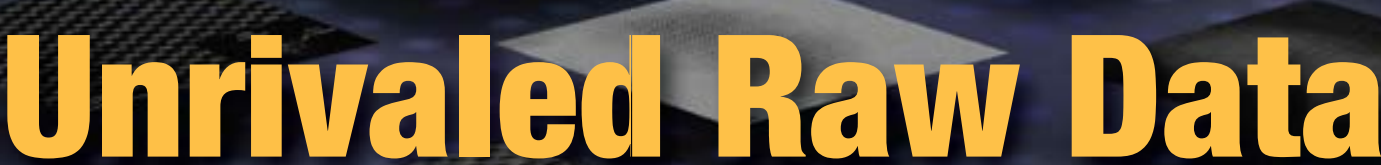 You Can Believe: .}

\section{Cold FEG* S/TEM sets a new benchm
for aberration-corrected tmaging and chemical mapping.}

Raw high angle annular darkfield (HAADF) STEM image of Si (112) showing 78 pm point-topoint resolution.

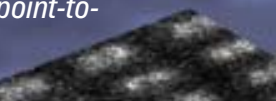

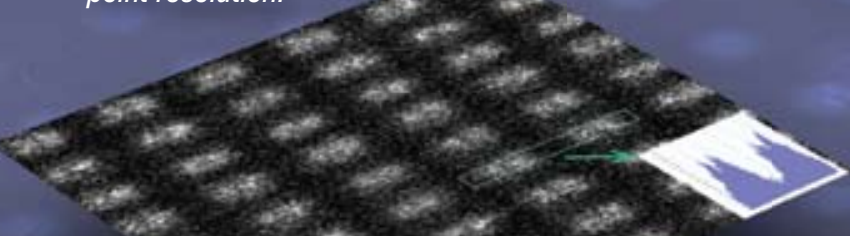
3. की 0.25

Raw high angle annular dark field (HAADF)

STEM image of Si (110) at $80 \mathrm{kV}$.

\section{the raw data is yours!}

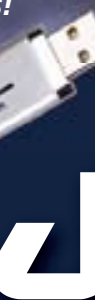

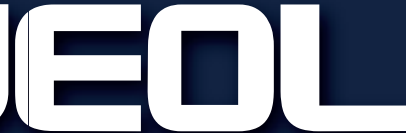

1 